Gdańsk 2020, Nr. 43

https://doi.org/10.26881/sgg.2020.43.11

Agnieszka Poźlewicz

Universität Poznań / Uniwersytet im. Adama Mickiewicza w Poznaniu

ORCID: 0000-0002-2607-0811

\title{
Mittel textuellen Exponierens im Deutschen und im Polnischen am Beispiel von Abgeordnetenreden in parlamentarischen Debatten
}

Der Beitrag setzt sich zum Ziel, Mittel textuellen Exponierens im Deutschen und im Polnischen zu untersuchen und anschließend zu klassifizieren. Unter dem Terminus Exponieren ist die sprachliche Hervorhebung eines informativ signifikanten (Sachverhalts)elements einer Äußerung (in Gestalt von Wörtern, Phrasen oder sogar ganzen Sätzen) zu verstehen, die unter Nutzung verschiedener, u. a. lexikalischer, phrasemischer oder topologisch-syntaktischer Mittel erfolgt. Die empirische Basis für die Untersuchung bilden Abgeordnetenreden parlamentarischer Plenardebatten im Bundestag und im Sejm.

Schlüsselwörter: Exposition, expositive Partikeln, deutsche und polnische Syntax, Clefting, Abgeordnetenrede

The means of textual emphasis in German and Polish on the example of parliamentary speeches. - The article deals with linguistic means used in German and Polish to emphasize a certain element in the text (such as a word, a phrase or the whole utterance). The analysed data consist of extracts from parliamentary speeches made by MPs in German Bundestag and Polish Sejm. The aim of the paper is to investigate different linguistic means of textual emphasis in German and Polish (e.g. syntactic, lexical and rhetorical ones) in order to elaborate their subclassification and to show the similarities and differences in their usage in both languages.

Keywords: emphasis, emphasizing particles, German and Polish syntax, clefting, parliamentary speech

\section{Zielsetzung und Untersuchungsgegenstand}

Der Beitrag setzt sich zum Ziel, Mittel textuellen Exponierens im Deutschen und im Polnischen am Beispiel von Abgeordnetenreden in parlamentarischen Plenardebatten im Bundestag und im Sejm zu untersuchen und anschließend zu klassifizieren. Dabei verstehe ich unter dem Terminus Exponieren die sprachliche Hervorhebung eines informativ signifikanten (Sachverhalts)elements einer Äußerung, die unter Nutzung verschiedener Mittel auf allen Ebenen des Sprachsystems erfolgt. Diesem kommunikativen Vorgehen liegt nach Cirko (2013: 55) die Absicht zugrunde, „Wichtiges von dem unwichtigen Informationshintergrund abzuheben“ und somit die Aufmerksamkeit des Textrezipienten auf einen Inhalt zu lenken (vgl. Dalmas 2013: 68). 
Die empirische Basis der von mir durchgeführten Untersuchung bilden 16 deutsche Abgeordnetenreden aus den Plenarsitzungen des Deutschen Bundestags am 17.03.2016, 14.04.2016 und 21.11.2017 sowie 11 polnische Abgeordnetenreden aus den Plenarsitzungen des Sejms der Republik Polen am 10.12.2015, 21.12.2015, 20.10.2016 und 30.11.2016. Die Reden wurden ohne Rücksicht auf die Fraktionszugehörigkeit der Redner und die Thematik der einzelnen Tagesordnungspunkte analysiert; das einzige Kriterium war die Vielfalt der verwendeten Expositionsmittel. Bei der Analyse wird unidirektional verfahren, d. h. die Expositionsmittel im Deutschen werden mit ihren polnischen Entsprechungen konfrontiert.

Für die Zwecke der Analyse habe ich die Abgeordnetenreden niedergeschrieben und dabei den genauen Wortlaut des gesprochenen Redetextes beibehalten. Die Niederschrift der Redebeiträge habe ich anhand von Plenarprotokollen, d. h. sogenannten Stenografischen Berichten erstellt, die ich mit den entsprechenden Videoaufzeichnungen aus der Mediathek des Bundestages bzw. des Sejms verglichen habe.

\section{Die Textsorte Abgeordnetenrede}

Die Textsorte parlamentarische Abgeordnetenrede als „Prototyp der politischen Rede“ (Klein 1991: 268) bildet „den zentralen Schnittpunkt [...] zwischen den Interaktionsrahmen Gesetzgebung, parteiinterne Willensbildung und politische Werbung" (ebd.: 270). Die Spezifik dieser Textsorte beruht darauf, dass sie im Rahmen einer mehrfachadressierten Parlamentsdebatte geäußert wird und sich daher ,in der Regel sowohl an die physisch Anwesenden ('innere Öffentlichkeit') als auch an die über die Medien präsente Öffentlichkeit der Bürger ('äußere Öffentlichkeit') sowie darüber hinaus an die politisch Verantwortlichen anderer Staaten ('externe Öffentlichkeit') richtet" (Burkhardt 2003: 280). Da die Parlamentsdebatte über die Massenmedien jedem zugänglich ist, sind ihre eigentlichen Adressaten die Bürger und somit potentielle Wähler, vor denen die Politiker ihre eigene Position zu legitimieren suchen (vgl. Klein 2001: 1594).

Die parlamentarische Abgeordnetenrede lässt sich den konzeptionell schriftlichen Texten im mündlichen Medium zuordnen (vgl. Koch / Oesterreicher 1985), denn sie wird zwar mündlich vorgetragen, aber die Debattenbeiträge sind nicht selten schriftlich vorbereitet, in einigen Fällen sogar wörtlich. Anzumerken ist an dieser Stelle allerdings, dass nach der Geschäftsordnung des Bundestages „das Verlesen schriftlich vorbereiteter Redetexte“ (Zeh 1989: 934) eigentlich nicht erlaubt ist (vgl. GOBT $\left.{ }^{1} 2014, \S 33\right)$. Gefordert wird vielmehr „der freie Vortrag gleichsam als Element parlamentarischer Kultur“ “(Zeh 1989: 934). Die Redner sollen „grundsätzlich in freiem Vortrag [sprechen] “, sie können allerdings „, hierbei Aufzeichnungen benutzen“ (GOBT, 2014), so dass in verschiedenem Grade frei gesprochene Redebeiträge anzunehmen sind.

Ein Korpus von mündlich realisierten, aber schriftlich konzipierten und daher „gewissermaßen rhetorisch gestaltet[en]" (Tworek 2016: 226) Abgeordnetenreden ist auf die Spezifik des zu untersuchenden Problems zugeschnitten, denn es ist zu erwarten, dass die persuasive Wirkung solcher Texte durch Exposition bestimmter Sachverhaltselemente intensiviert wird.

1 https://www.bundestag.de/parlament/aufgaben/rechtsgrundlagen/go_btg [30.11.2019]. 


\section{Analyse des gesammelten Materials}

\subsection{Lexikalische Expositionsmittel}

Unter den lexikalischen Mitteln sind in erster Linie expositive Operatorpartikeln zu nennen, die „der Hervorhebung des Elements in ihrem Skopus dienen“" (Poźlewicz 2011: 144).Zu dieser Klasse gehören unter anderem die wohl synonymen und oft austauschbaren Partikeln vor allem, besonders und insbesondere, die exponieren, „ohne dabei Alternativen zu exkludieren und so signalisieren, dass ihr Operand Exemplar einer ungeordneten Menge der möglichen Skopuserfüllungen ist, das Gesagte aber für diesen Operanden in besonderer Weise gilt" (ebd.: 62). Ihre hervorhebende und zugleich inklusive Leistung veranschaulichen folgende Belege. Der Notation der Belege ist vorwegzunehmen, dass diese in ihrem Originalwortlaut des gesprochenen Redebeitrags angeführt sind, allerdings ohne Berücksichtigung der eventuellen Sprechsilbenfehler. In allen Belegen sind die analysierten Abschnitte fett markiert und das in ihnen Exponierte durch Sperrdruck hervorgehoben.

(1) In Ihrem Antrag ist die Rede von mindestens 100000 Vollzeitstellen in der Pflege, die Sie schaffen wollen. Bei diesen Zahlenspielen bleibt aber offen, woher Sie das Geld nehmen und woher Sie vor allem das ausgebildete Pflegepersonal bekommen sollen. (Erich Irlstorfer, 161. Sitzung am 17.03.2016)

(2) Der Zugang zur beruflichen Weiterbildung für geringqualifizierte Arbeitnehmerinnen und Arbeitnehmer, Langzeitarbeitslose und Ältere werden verbessert und damit die berufliche Qualifikation enorm erhöht. Ich halte es persönlich für sehr wichtig, dass wir vor allem die meist jungen Erwerbstätigen ohne Berufsabschluss in den Fokus nehmen. (Albert Weiler, 164. Sitzung am 14.04.2016)

(3) Im Zuge der Globalisierung ist Wirtschaft weltweit in den Produktions-, Liefer- und Dienstleistungsketten sehr weit verzweigt. Insbesondere lohnkostenintensive Arbeiten werden oft in den Entwicklungs- und Schwellenländern Asiens oder Afrikas erledigt. (Elvira Drobinski-Weiß, 164. Sitzung am 14.04.2016)

(4) Mit dieser Erkenntnis laufen Sie bei uns und insbesondere bei mir wirklich offene Türen ein. (Brigitte Pothmer, 164. Sitzung am 14.04.2016)

(5) Und Sie haben recht, wenn Sie sagen - das beschreiben Sie selbst -, dass besonders di i jenigen, die eine Weiterbildung notwendig hätten, dass gerade die in diesen Angeboten nicht zu finden sind und vollkommen unterrepräsentiert sind. Das muss sich ändern. (Brigitte Pothmer, 164. Sitzung am 14.04.2016)

$\mathrm{Zu}$ den hervorhebenden Partikeln (partykuty wyróżniające) im Polnischen indessen rechnet Kisiel (2012) gtównie ('hauptsächlich', 'vor allem'), przede wszystkim ('vor allem'), zwtaszcza ('zumal', 'insbesondere,' 'vor allem'), szczególnie und w szczególności ('besonders', 'insbesondere'). Die semantische Leistung dieser Partikelklasse erklären Grochowski u. a. (2014: 272) wie folgt: „das, was ich sage, ist wichtiger als alles andere“ (Übers.: A.P.). Somit wirken die polnischen Partikeln - ähnlich ihren deutschen Pendants - sekundär auch inklusiv, denn es ist nicht ausgeschlossen, dass das Gesagte auf andere Größen zutrifft, wenn auch nicht in demselben Grad. 
Diese Leistung illustrieren folgende Belege aus den Abgeordnetenreden im polnischen Sejm, in denen Nominal- bzw. Präpositionalphrasen als das Wichtigste aus einer Menge anderer in Frage kommenden Elemente hervorgehoben werden:

(6) Te zasady, tak szeroko wprowadzone w tamtej ustawie, jak i przeniesione do tej ustawy przez analogię, jak to zostało wytłumaczone, one pogarszają konkurencyjność polskiego rynku, a przede wszystkim biją w polską przedsiębiorczość. (Antoni Mężydło, 28. Sitzung am 20.10.2016)

(7) Ustawa ta jest kluczowa przede wszystkim dla wielu milionów Polaków, których kwalifikacje - przede wszystkim kwalifikacje cząstkowe - byłyby uznawane nie tylko w Polsce, ale także w całej Unii Europejskiej. (Krystyna Wróblewska, 6. Sitzung am 21.12.2015)

(8) Proszę państwa, tzw. kredyty walutowe stanowiły dla sektora bankowego źródło istotnych korzyści finansowych, które w pewnej mierze wynikają ze stosowania w umowach kredytowych postanowień o charakterze abuzywnym, godzących w dobre obyczaje i w rażący sposób naruszających interesy kredytobiorców, konsumentów. Mowa w szczególności o dowolności w przeliczaniu kapitału i raty kapitału po kursach ustalonych w sposób jednostronny, proszę państwa, przez banki. (Andrzej Maciejewski, 28. Sitzung am 20.10.2016)

(9) Proszę państwa, w związku z tym, że po prostu nie panujecie, szczególnie PiS, w ogóle nie panujecie już nad tym bałaganem, który żeście zafundowali ... (Jerzy Meysztowicz, 6. Sitzung am 21.12.2015)

(10) Mimo że dzisiaj pan premier Morawiecki tak bardzo troszczył się o zasady poprawiające przedsiębiorczość w Polsce, szczególnie tych firm prywatnych, to jednak uderza tutaj głównie w firmy prywatne i tak naprawdę preferuje głównie te firmy samorządowe. (Antoni Mężydło, 28. Sitzung am 20.10.2016)

(11) Tak jak przedstawiłem już, proponowana ustawa o zamówieniach publicznych i koncesji na roboty budowlane w dzisiejszej rzeczywistości jest bardzo istotną ustawą, która otwiera możliwość inwestowania, głównie przez sa morządy, bez konieczności inwestowania własnych środków. (Waldemar Olejniczak, 28. Sitzung am 20.10.2016)

(12) Niestety po tych kilkunastu latach doświadczeń związanych z Kartą Polaka wiemy, że nie zawsze ona trafia w powołane ręce, często jest wykorzystywana przez osoby, które traktują ją tylko i wyłącznie jako taką trampolinę do Polski, ale z polskością tak naprawdę nie mają wiele wspólnego, zwłaszcza teraz, po nowelizacji, która daje dodatkowe uprawnienia. (Wojciech Bakun, 28. Sitzung am 20.10.2016)

Anzumerken ist zu diesen Belegen, dass die hervorhebenden Partikeln auch Einschübe eröffnen können und somit der Autokorrektur bzw. der Präzisierung des vorher Gesagten dienen, wie etwa przede wszystkim in Beleg (7) oder zwtaszcza in Beleg (12), in dem die exponierte Temporalangabe teraz po nowelizacji im Weiteren mit einem Relativsatz präzisiert wird.

Hinzuweisen ist darüber hinaus auf die expositive Operatorpartikel geschweige denn, die signalisiert, dass „die Nichterfüllung der Proposition für das hervorgehobene Element $[\ldots]$ als erwartet und weniger überraschend als für die im vorausgehenden Kontext genannte Alternative [gilt]“ (Poźlewicz 2011: 110). Das illustriert folgender Beleg, in dem der Redner die vor Afrika stehenden Herausforderungen hierarchisiert und eine von ihnen hervorhebt:

(13) Und schon heute ist der Kontinent nicht in der Lage, die Menschen zu ernähren, geschweige denn, ihnen echte Perspektiven zu bieten. (Thorsten Frei, 164. Sitzung am 14.04.2016)

Mit der Partikel wird signalisiert, „dass die Graduierung prinzipiell vom Wahrscheinlicheren hin zum weniger Wahrscheinlichen geht, die relative Wahrscheinlichkeit des Vorkommens der beiden Sachverhalte also abnimmt" (Eggs 2011: 244). Das Wahrscheinlichere, 
d. h. die Fähigkeit des Kontinents, die Menschen in Afrika zu ernähren, trifft nicht zu, woraus sich ergibt, dass das weniger Wahrscheinliche, also den Menschen dort echte Perspektiven zu bieten, schon gar nicht zutrifft. Durch diese Übertreibung „, [erhält] das Argument als Ganzes mehr Gewicht, d. h. mehr Persuasivität" (Eggs 2011: 246).

Im Polnischen entspricht geschweige denn die Partikel co dopiero, die oft mit dem adversativen Konjunktor $a$ eingeleitet wird (vgl. Grochowski u. a. 2014: 310). Ähnlich wie ihr deutsches Pendant signalisiert sie, „dass die für den vorhergehenden Satz geltende Negation bzw. Restriktion erst recht für das eingeführte Segment gilt“" (Métrich / Faucher 2009: 415). Das zeigt folgender Beleg, in dem die Nominalphrase reguta wydatkowa exponiert wird:

(14) Chciałam tylko powiedzieć, że PiS, jak pokazały cztery pierwsze posiedzenia Sejmu, był w stanie popsuć więcej rzeczy niż stabilizująca reguła wydatkowa i pokazuje swoim działaniem, że nie ma dla niego ani prawa, ani świętości. Ani konstytucja, ani Trybunał Konstytucyjny, nic nie jest świętością dla PiS-u, co dopiero reguła wydatkowa. (Izabela Leszczyna, 4. Sitzung am 10.12.2015)

Ähnlich wie in Beleg (13) wird hier ebenfalls eine Reihe der immer weniger wahrscheinlichen Sachverhalte signalisiert: Das Wahrscheinlichere, d. h. das Befolgen der Regeln des Grundgesetzes, trifft nicht zu, so dass das Nichtzutreffen des weniger Wahrscheinlichen, d. h. des Befolgens der Ausgabenregel, nicht mehr überrascht, was der so geäußerten Kritik mehr Nachdruck verleiht. Die Leistung der Partikel wird zusätzlich durch die Aufzählung mit dem wiederholten additiven Konjunktor ani ... ani verstärkt.

$\mathrm{Zu}$ den lexikalischen Expositionsmitteln gehören darüber hinaus die mehrteiligen additiven Konjunktoren: Der deutsche Konjunktor sowohl..., als / wie auch und seine polnische Entsprechung zarówno ..., jak $i$ gelten als „nachdrückliches und“ (Eisenberg u. a. 2009: 622) und dienen der Hervorhebung beider Konjunkte (vgl. Rytel-Schwarz u. a. 2012: 153), wie etwa in folgenden Belegen:

(15) Wir sagen: 250000 Sozialwohnungen müssen neu entstehen - ich betone: sowohl für die deutsche Bevölkerung als auch für Migranten und Geflüchtete. (Caren Lay, 161. Sitzung am 17.03.2016)

(16) Das Land am Horn von Afrika braucht internationale Unterstützung, sowohl bei der Stabilisierung der Sicherheitslage als auch beim Aufbau eigener Sicherheitsstrukturen. (Julia Obermeier, 161. Sitzung am 17.03.2016)

(17) 2013 wurde der sogenannte New Deal for Somalia zwischen der Regierung und internationalen Geldgebern verabschiedet. Dadurch werden sowohl die somalische Zivilgesellschaft wie auch die Wirtschaft und staatliche Strukturen gestärkt. (Gabi Weber, 161. Sitzung am 17.03.2016)

(18) Ja chciałem nadmienić, iż realizując tę ustawę w całości, miałem przyjemność kierować podkomisją, następnie byłem członkiem komisji. W trakcie tych procedur współpraca zarówno z opozycją, jakiz wszystkimi grupami społeczny mi, wszystkimi komitetami, komisjami i przedstawicielami wszystkich klubów układała się bardzo dobrze. (Waldemar Olejniczak, 28. Sitzung am 20.10.2016)

(19) Wielokrotnie dyskutowaliśmy zarówno na tej sali, jaki w komisjach sejmowych na ten temat. (Wojciech Bakun, 28. Sitzung am 20.10.2016)

(20) Nie ma przed tym zabezpieczeń i jako Klub Poselski Kukiz'15 popieramy tę poprawkę, natomiast apelujemy tutaj zarówno do komisji, jaki do członków partii rządzącej, żeby pochylić się nad tym problemem. (Wojciech Bakun, 28. Sitzung am 20.10.2016) 
Mit dem deutschen Konjunktor nicht nur ..., sondern auch und seinem polnischen Pendant nie tylko ..., ale / lecz także indessen wird „die Exklusivität des ersten Elements [...] negiert, die Geltung des zweiten Elementes wird hervorgehoben“" (Rytel-Schwarz u. a. 2012: 151), was folgende Belege veranschaulichen:

(21) Eine einseitige Konzentration auf Mietwohnungen greift sicher auch zu kurz. Wir brauchen auch die Eigentumsförderung. Und es gibt eben nicht nur die eine Maßnahme, das eine Instrument, sondern wir brauchen ein Bündel von Maßnahmen. (Anja Weisgerber, 164. Sitzung am 14.04.2016)

(22) Ich möchte - und ich denke, da sind wir uns einig - nicht nur in einer sicheren Gesellschaft leben, sondern auch in einer men schlichen Gesellschaft. Und dieser Gesetzentwurf wird dazu einen Beitrag leisten. (Kirsten Lühmann, 164. Sitzung am 14.04.2016)

(23) Ale mimo tego wysiłku, który ponieśliśmy, w dalszym ciągu przepisy są naszym zdaniem nieczytelne w wielu miejscach. One są nieczytelne nie tylko dla podatników, one tak na dobrą sprawę, nie tylko dla zewnętrznych wobec tego odbiorców, ale także i dla tych wewnętrznych, dla samych pracowników organu. (Janusz Cichoń, 28. Sitzung am 20.11.2016)

(24) Unia Europejska to dobrowolny sojusz niepodległych państw, związanych nie tylko w celu zniesienia barier handlowych, ale także w celu wzajemnego, solidarnego pomagania sobie w rozwiązywaniu problemów. (Tomasz Głogowski, 28. Sitzung am 20.10.2016)

(25) A więc ustawa obejmuje kredyty długoterminowe z reguły zabezpieczone hipotecznie i dotyczy umów kredytowych, które zostały w całości wykonane lub wypowiedziane. Dotyczy nie tylko konsumentów w rozumieniu Kodeksu cywilnego, ale także innych osób fizycznych, które zawarły umowę kredytową w związku z prowadzoną przez siebie działalnością gospodarczą. (Genowefa Tokarska, 28. Sitzung am 20.10.2016)

\subsection{Phrasemische Expositionsmittel}

Zu den phrasemischen Expositionsmitteln gehören unter anderem feste Präpositionalphrasen wie in erster Linie und vor allen Dingen, die in ihrer Leistung den bereits besprochenen Operatorpartikeln vor allem und besonders ähneln. Das illustrieren folgende Redeabschnitte, in denen die zum Kontrast angegebenen attributiven Präpositionalphrasen für bezablbares Bauen und für bezablbares Wohnen in Beleg (26) sowie die Nominalphrasen den Patientinnen und Patienten in Beleg (27) und Mehrheiten hier in der Bundesregierung und in der Großen Koalition in Beleg (28) hervorgehoben werden:

(26) Im Bericht werden auch einige gute Vorschläge gemacht. Für mich ist aber so bisschen die Frage, ist das am Ende ein Bericht in erster Linie für bezahlbares Bauen oder ist es in erster Linie ein Bericht für bezahlbares Wohnen. (Caren Lay, 161. Sitzung am 17.03.2016)

(27) Und warum ist uns die Verbesserung der Qualität besonders wichtig? Weil sie vor allem jenen dient, um die es im Gesundheitswesen in erster Linie geht: den Patientinnen und Patienten. (Marina Kermer, 161. Sitzung am 17.03.2016)

(28) Wir brauchen einen Neustart im sozialen und gemeinnützigen Wohnungsbau; aber dafür müssen wir vor allen Dingen Mehrheiten hier in der Bundesregierung und in der Großen Koalition finden. (Caren Lay, 161. Sitzung am 17.03.2016)

Zum Beleg (27) ist anzumerken, dass in diesem mehrfache Exposition vorliegt. Im ersten Schritt bedient sich die Rednerin hier der Operatorpartikel vor allem, in deren Skopus 
das kataphorisch verweisende Demonstrativpronomen jenen steht. Das mit dem Pronomen Gemeinte wird dann zum einen mit dem Relativsatz um die es im Gesundheitswesen geht und zum anderen mit der nachgetragenen Nominalphrase den Patientinnen und Patienten expliziert. Die somit nach rechts herausgestellte Phrase wird zusätzlich mit in erster Linie exponiert. Die Leistung der exponierenden Abtrennung wird im Vergleich mit einem entsprechenden Satz ohne Herausstellung umso deutlicher:

(27’) Im Gesundheitswesen geht es in erster Linie um Patientinnen und Patienten.

Auch im polnischen Analysematerial finden sich Belege für die Verwendung phrasemischer Expositionsmittel, wie etwa die dem Deutschen entlehnte lexikalisierte Präpositionalphrase w pierwszym rzędzie ('in erster Linie'), mit der das Präpositionalobjekt o takie osoby hervorgehoben wird. In ihrer Leistung ähnelt diese Phrase hervorhebenden Partikeln wie etwa przede wszystkim:

(29) Pytam, bo przecież państwo w pierwszym rzędzie powinno dbać o takie osoby. (Barbara Chrobak, 31. Sitzung am 30.11.2016)

Im ausgewerteten Material finden sich darüber hinaus hervorhebende pragmatische Phraseologismen, wie beispielsweise die deutsche Infinitivkonstruktion von jemandem/etwas ganz $z u$ schweigen und die als ihre Entsprechung im Polnischen geltende Partizipialkonstruktion nie mówiac już $o$ :

(30) Ebenfalls seit Jahren sammle ich anonymisierte Gefährdungsanzeigen. Sie werden von den Pflegekräften erstellt, wenn es zur gefährlichen Pflege kommt, wenn eine Gefährdung der Patientinnen und Patienten und der Pflegebedürftigen vorliegt, von der Gefährdung der Pflegekräfte ganz zu schweigen. (Harald Weinberg, 2. Sitzung am 21.11.2017)

(31) Fakty są następujące: zaproponowana konstrukcja umowy, instrumentu jest takim dzieckiem, że tak naprawdę bank nie ponosi żadnego ryzyka, a wszystkie umowy są tak skonstruowane, że łamią zasady konstytucji, Kodeksu cywilnego, ustawy o prawie bankowym, a nawet konsumenckie prawa unijne, nie mówiąc już o trybunałach. (Andrzej Maciejewski, 28. Sitzung am 20.10.2016)

(32) W praktyce oznacza to, że zanim osoba z niepełnosprawnością otrzyma zasiłek, mija bardzo dużo czasu. Często są to długie miesiące bez środków na zabezpieczenie podstawowych potrzeb, nie mówiąc już o potrzebach ponadstandardowych, a te są normą w przypadku osób niepełnosprawnych. (Barbara Chrobak, 31. Sitzung am 30.11.2016)

Beiden Phrasen ist gemeinsam, dass sie in der Regel bei Aufzählungen von Argumenten verwendet werden und den Sprecher betonen lassen, dass er seine Aussage mit zusätzlichen Ausführungen stützen kann (vgl. Poźlewicz 2014: 114). In ihrer Leistung ähneln sie den bereits erwähnten Partikeln geschweige denn und co dopiero, da sie auch eine Graduierung der Argumente vom Wahrscheinlicheren hin zum weniger Wahrscheinlichen signalisieren und somit dem Argument mehr Gewicht geben (vgl. Eggs 2011: 246).

Um die Aufmerksamkeit des Publikums auf die hervorzuhebende Folgeäußerung zu lenken, bedienen sich die Redner außerdem pragmatischer Phraseologismen wie Achtung im Deutschen oder uwaga im Polnischen. In beiden Sprachen sind diese Routineformeln als Aufmerksamkeitssignale in den Satz nicht integriert und stehen als parenthetische Einschübe direkt vor dem exponierten Element. Der Veranschaulichung ihrer Leistung dienen folgende 
Belege, in denen die zusätzlich wiederholte Nominalphrase eine Verfolgung und die attributive Nominalphrase (przeliczenie) rat kapitatowo-odsetkowych hervorgehoben sind:

(33) Weiter sagt das Bundesverfassungsgericht: Eine Einstufung ist nicht zulässig, wenn regional oder im Hinblick auf bestimmte Gruppen eine Verfolgung - Achtung - eine Verfolgung nicht ausgeschlossen werden kann. (Luise Amtsberg, 164. Sitzung am 14.04.2016)

(34) Umowa kredytu przewiduje przeliczenie kwoty kredytu ze złotówek na franki po kursie kupna waluty, natomiast, uwaga, rat kapitałowo-odse tkow ych - z franka na złotówki po kursie sprzedaży waluty. (Andrzej Maciejewski, 28. Sitzung am 20.10.2016)

In Beleg (35) bedient sich der Redner des pragmatischen Phraseologismus sogar zweimal erstens, um auf die zitierte Feststellung der Nationalbank aufmerksam zu machen, und zweitens, um die Präpositionalphrase $w$ ztotych hervorzuheben:

(35) Kredyty udzielone w tzw. frankach są kredytami złotówkowymi indeksowanymi lub denominowanymi do waluty obcej. I teraz, uwaga, 6 lipca 2011 r. przy okazji pracy nad ustawą spreadową na rodowy bank stwierdza: Należy zauważyć, że kredyt w walucie polskiej, denominowany lub indeksowany w innej walucie niż polska, jest kredytem - uwaga - w złotych. (Andrzej Maciejewski, 28. Sitzung am 20.10.2016)

$\mathrm{Zu}$ den phrasemischen Mitteln gehören nicht zuletzt metakommunikative Expositionsdeklarationen, mit denen der Sprecher etwas explizit hervorheben kann. Solche Formeln mit Verben wie hervorheben, betonen, unterstreichen und wiederholen im Deutschen sowie podkreślić und powtórzyć im Polnischen, in beiden Sprachen häufig in der Kombination mit einem Modalverb, sind entweder Einleitungsformeln, d. h. Trägersätze für einen abhängigen Satz wie etwa in Belegen (36), (38), (40), (41) und (42), oder sie gelten als Einschübe, wie in Belegen (37), (39), (43) und (44).

(36) Aber frei nach Erich Kästner: „Wo bleibt denn das Positive, Frau Pothmer?“, möchte ich erstmal zwei Punkte hervorheben, die ich ausdrücklich unterstütze. Und das ist der Vorrang der Weiterbildung vor Vermittlung, mindestens bei Arbeitslosen ohne eine Berufsausbildung. (Brigitte Pothmer, 164. Sitzung am 14.04.2016)

(37) Wir sagen: 250000 Sozialwohnungen müssen neu entstehen - ich betone: sowohl für die deutsche Bevölkerung als auch für Migranten und Geflüchtete. (Caren Lay, 161. Sitzung am 17.03.2016)

(38) Hier will ich unterstreichen, dass der Union das Thema selbstgenutztes Wohneigentum ein besonderes Anliegen ist. (Georg Nüßlein, 161. Sitzung am 17.03.2016)

(39) Und da ist und bleibt - das möchte ich auch nochmal wiederholen - unser wohnungspolitischer Dreiklang sicherlich die geeignete und richtige Antwort und das geeignete Leitbild. (Anja Weisgerber, 164. Sitzung am 14.04.2016)

(40) Także chciałbym bardzo wyraźnie podkreślić: to, że Platforma Obywatelska była i jest przeciwko automatyzmowi w narzucaniu państwom liczby przyjętych uchodźców, nie znaczy, że zgadzamy się na politykę strachu i chowania głowy w piasek. (Tomasz Głogowski, 28. Sitzung am 20.10.2016)

(41) Tak więc prezydent zawiódł. Zresztą to chyba nie jest jedyny przypadek, kiedy zawiódł, mówił co innego, a zrobił jeszcze coś innego. Podkreślić również trzeba, Wysoka Izbo, powiedzieć bardzo dobitnie, że w całej tej tematyce zawiodły przede wszystkim banki, instytucje zaufania publicznego. I nie można tego problemu rozwiązać bez konsekwencji dla banków, które przecież wyspecjalizowały się w tej szkodliwej ofercie dla kredytobiorców. (Genowefa Tokarska, 28. Sitzung am 20.10.2016) 
(42) I jeszcze chciałam podkreślić, że jako klub Prawo i Sprawiedliwość będziemy bacznie patrzeć, jak ta ustawa będzie funkcjonować. Jeżeli będzie funkcjonować nie za dobrze, będziemy dokonywać jej ewaluacji i wnosić poprawki. (Krystyna Wróblewska, 6. Sitzung am 21.12.2015)

(43) Opinia rzecznika finansowego ponadto stwierdza: Co się tyczy kursów, na podstawie których ustalone są kursy kupna i sprzedaży walut - ustalone jednostronnie, proszę państwa, jeszcze raz powtarzam, jednostronnie - przez bank, na które konsument nie ma żadnego wpływu, mogą być (one) uznane za klauzule - jakie? - abuzywne. (Andrzej Maciejewski, 28. Sitzung am 20.10.2016)

(44) Państwo powinno ten fakt mieć na uwadze i zachować szczególną wrażliwość, powtarzam, szczególną wrażliwość wobec potrzeb osób wykluczonych z uwagi na niepełnosprawność. (Barbara Chrobak, 31. Sitzung am 30.11.2016)

$\mathrm{Zu}$ den Belegen (43) und (44) ist zudem anzumerken, dass sich die Sprecher in diesen des stilistischen Expositionsmittels der wörtlichen Wiederholung bedienen, was sie mit dem eingeschobenen Finitum powtarzam signalisieren. Die Wiederholung des Adverbs jednostronnie in (43) und der Nominalphrase szczególnq wrażliwość in (44) dient einerseits dem Nachdruck und Hervorhebung, andererseits aber auch der Sicherstellung, dass das Gesagte an den Hörer übermittelt wird (vgl. Friesdorf 2011: 74).

\subsection{Topologisch-syntaktische Expositionsmittel}

Abschließend ist auf topologisch-syntaktische Expositionsmittel einzugehen, mit denen „ein Element nach außerhalb des Satzverbandes verschoben und somit informativ hervorgehoben wird" (Cirko 2013: 55). Im ausgewerteten Material beider Sprachen finden sich Belege für die Satzspaltung, die als „eine Variante der Herausstellung“ (ebd.: 59) auf der syntaktischen Umformung im Sinne von „'Umwandelung' eines zugrunde liegenden Simplexsatzes in ein semantisch gleichbedeutendes Satzgefüge" (Engebretsen 2016: 43) beruht. Dabei wird ein hauptsächlich nominales Satzelement aus einem einfachen Satz abgespalten und in einen Kopulasatz eingefügt (vgl. Altmann / Hofmann 2008: 152).

Den Terminus Satzspaltung verwende ich in Anlehnung an Engel (2009: 181) als Oberbegriff für Clefting und Pseudo-Clefting. In beiden Fällen handelt es sich um komplexe bi-klausale „Konstruktionen, bei denen ein bestimmtes Element aus dem Satz herausgestellt wird, um die Aufmerksamkeit darauf zu lenken, es zu fokussieren oder einen Kontrast zu markieren "(Günthner 2006: 61). Der Unterschied zwischen ihnen besteht aber in der Reihenfolge der Teilsätze.

Ein Cleft-Satz besteht demzufolge aus einem übergeordneten Kopulasatz und einem immer nachgestellten Relativsatz. Den übergeordneten Satz bilden das obligatorische es, eine finite Form des Kopulaverbs sein und ein nach links herausgestelltes Element, d. h. die sogenannte Cleft-Konstituente, die prototypisch eine nominativische Nominalphrase „unterschiedlichster Komplexitätsstufen“" (Altmann 2009: 17) ist. Dies illustrieren folgende Belege, in denen die Nominalphrasen der richtige Weg und die Mieterinnen und Mieter abgespalten und somit hervorgehoben werden:

(45) Ich glaube, es ist der richtige Weg, den wir hier einschlagen. (Thorsten Frei, 164. Sitzung am 14.04.2016) 
(46) Die Mieterinnen und Mieter sind es, die das politische Versagen der letzten Jahrzehnte ausbaden müssen. (Caren Lay, 161. Sitzung am 17.03.2016)

Die hervorhebende Leistung des Cleftings wird im Vergleich mit den analogen einfachen Sätzen deutlich:

(45’) Ich glaube, wir schlagen hier den richtigen Weg ein.

(46') Die Mieterinnen und Mieter müssen das politische Versagen der letzten Jahrzehnte ausbaden.

Dem deutschen Clefting entsprechen im Polnischen Konstruktionen mit der expositiven Partikel to (vgl. Cirko 2013: 60), was folgender Beleg illustriert:

(47) Projektowana ustawa jest konsekwencją potrzeby wdrożenia wyroku Trybunału Konstytucyjnego z 6 października 2015 roku. To właśnie ten wy rok zakwestionował zasadę przyznawania zasiłku stałego dla niepełnosprawnych dopiero od momentu złożenia wniosku do ośrodka pomocy społecznej wraz z pełną dokumentacją. (Barbara Chrobak, 31. Sitzung am 30.11.2016)

Mit der Partikel to, die im analysierten Redeabschnitt noch von der expositiven Partikel wtaśnie (i. S. v. 'gerade', 'eben') zusätzlich verstärkt wird, hebt die Rednerin die Nominalphrase ten wyrok hervor. Eine Übersetzung des Belegs ins Deutsche bestätigt, dass eine solche Konstruktion dem Clefting im Deutschen ähnlich ist:

(47’) Es war gerade dieses Urteil, das die Regeln zur Gewährung einer Dauerbeihilfe für Behinderte in Frage stellte.

Die hervorhebende Leistung der Partikel to wird beim Vergleich mit einem umformulierten Satz umso deutlicher:

(47”) (Właśnie) ten wyrok zakwestionował zasadę przyznawania zasiłku stałego dla niepełnosprawnych.

Beim Pseudo-Clefting indessen geht der Relativsatz dem Kopulasatz voraus (vgl. Birkner 2008: 325). Der Veranschaulichung dienen folgende Belege, in denen die Nominalphrasen die Reform der Pflegeausbildung und eine inklusive Gesellschaft nach rechts versetzt und somit hervorgehoben werden:

(48) Und über die reale Einführung von Personalbemessungsinstrumenten, da verlieren Sie in diesem Gesetz kein Wort. Was Sie aber wortreich versuchen schönzureden, das ist die Reform der Pflegeausbildung. (Elisabeth Scharfenberg, 161. Sitzung am 17.03.2016)

(49) Was wir aber brauchen, ist eine inklusive Gesellschaft, heute mehr denn je. (Corinna Rüffer, 161. Sitzung am 17.03.2016)

Die hervorhebende Leistung des Pseudo-Cleftings wird im Vergleich mit den analogen „entspalteten“" einfachen Sätzen umso deutlicher:

(48') Sie versuchen aber die Reform der Pflegeausbildung wortreich schönzureden.

(49’) Wir brauchen aber eine inklusive Gesellschaft.

Auch im Polnischen wird eine ähnliche biklausale Konstruktion verwendet, die aus einem mit co eingeleiteten Relativsatz und einem übergeordneten Kopulasatz besteht. Rytel-Schwarz u. a. 
(2018: 437) weisen allerdings darauf hin, dass das hervorgehobene Element „als Subjekt eines Kopulasatzes [...] häufig mit Korrelat/Bezugswort", meistens to, erscheint. Das veranschaulichen folgende Belege, in denen das Nomen skandal und die Nominalphrase gigantyczny chaos w stużbach skarbowych in einen Kopulasatz versetzt und dadurch exponiert sind:

(50) To, co dzisiaj jest na Komisji Ustawodawczej, to jest po prostu skandal. My pracujemy nad ustawą, która jest zupełnie inna niż w pierwszym czytaniu. Są poprawki wniesione takie, które zmieniają w ogóle kształt tej ustawy. (Jerzy Meysztowicz, 6. Sitzung am 21.12.2015)

(51) To, co nas czeka, to gigantyczny chaos w służbach skarbowych i, moim zdaniem, skutki odwrotne do oczekiwanych. (Janusz Cichoń, 28. Sitzung am 20.11.2016)

Die Übersetzung der Belege ins Deutsche bestätigt die Ähnlichkeit der Strukturen in beiden Sprachen:

(50’) Was heute im Gesetzgebungsausschuss passiert, ist einfach ein Skandal.

(51') Was uns erwartet, ist ein riesiges Chaos im Steuerdienst.

Auch hier ist auf die analogen einfachen Sätze hinzuweisen, um die hervorhebende Leistung der Satzspaltung zu verdeutlichen:

(50") Dzisiaj na Komisji Ustawodawczej jest po prostu skandal.

(51") Czeka nas gigantyczny chaos w służbach skarbowych.

\section{Zusammenfassung}

Die Analyse der Abgeordnetenreden zeigt, dass der textuellen Exposition in beiden untersuchten Sprachen verschiedene Mittel dienen können, die mehrere Ebenen des Sprachsystems und -gebrauchs wie etwa Lexikon und Syntax repräsentieren. Die Expositionsmittel im Deutschen und ihre Pendants im Polnischen fasst folgende Tabelle zusammen:

\begin{tabular}{|c|c|}
\hline \multicolumn{2}{|c|}{ Expositionsmittel } \\
\hline im Deutschen & im Polnischen \\
\hline \multicolumn{2}{|c|}{ lexikalische Mittel } \\
\hline expositive Partikeln \\
$\begin{array}{c}\text { geschweige denn } \\
\text { besonders } \\
\text { insbesondere } \\
\text { vor allem }\end{array}$ & $\begin{array}{c}\text { co dopiero } \\
\text { gtównie } \\
\text { przede wszystkim } \\
\text { szczególnie } \\
\text { w szczególności } \\
\text { zwtaszcza }\end{array}$ \\
\hline sowohl ... als / wie auch & zarówno ..., jak i \\
\hline nicht nur ..., sondern auch & nie tylko ..., ale /lecz także additive Konjunktoren \\
\hline
\end{tabular}


Mittel textuellen Exponierens im Deutschen und im Polnischen...

\begin{tabular}{|c|c|}
\hline \multicolumn{2}{|c|}{ feste Präpositionalphrasen } \\
\hline $\begin{array}{l}\text { in erster Linie } \\
\text { vor allen Dingen }\end{array}$ & wpierwszym rzędzie \\
\hline \multicolumn{2}{|c|}{ pragmatische Phraseologismen } \\
\hline von jemandem/etwas ganz zu schweigen & nie mówiąc jużo \\
\hline Achtung & uwaga \\
\hline \multicolumn{2}{|c|}{ metakommunikative Expositionsdeklarationen } \\
\hline $\begin{array}{l}\text { ich möchte hervorheben } \\
\text { ich betone } \\
\text { ich will unterstreichen } \\
\text { ich möchte wiederholen }\end{array}$ & $\begin{array}{c}\text { chciatbym podkreślić } \\
\text { trzeba podkreślić } \\
\text { powtarzam }\end{array}$ \\
\hline \multicolumn{2}{|c|}{ topologisch-syntaktische Mittel } \\
\hline $\begin{array}{c}\text { Clefting } \\
\text { Kopulasatz }+ \text { Relativsatz }\end{array}$ & Konstruktionen mit der Partikel to \\
\hline \multicolumn{2}{|c|}{$\begin{array}{c}\text { Pseudo-Clefting } \\
\text { Relativsatz }+ \text { Kopulasatz }\end{array}$} \\
\hline
\end{tabular}

Verständlicherweise können die im Rahmen des vorliegenden Beitrags ausgewerteten Belege lediglich der Exemplifizierung dienen und sind quantitativ nicht auswertbar. In einer komplexeren konfrontativen Untersuchung wäre gewiss zu prüfen, inwieweit die dargestellten Subklassen der Expositionsmittel konsistent und exhaustiv sind. Einer umfassenden Überprüfung bedarf außerdem die Frage, welche sprachspezifischen Unterschiede zwischen deutschen und polnischen Mitteln textuellen Exponierens bestehen und ob kulturspezifische, und zwar allgemein kulturspezifische oder den politischen Diskurs kennzeichnende Unterschiede in der Verwendung der Expositionsmittel in deutschen und in polnischen Abgeordnetenreden festzustellen sind.

\section{Literatur}

Altmann, Hans (2009): Cleft- und Pseudocleft-Sätze (Spalt- und Sperrsätze) im Deutschen. In: BrdarSzabó, Rita / Knipf-Komlósi, Elisabeth / Péteri, Attila (Hg.): An der Grenze zwischen Grammatik und Pragmatik. Frankfurt/M.: Lang, 13-34.

Altmann, Hans / Hofmann, Ute (2008): Topologiefürs Examen. Verbstellung, Klammerstruktur, Stellungsfelder, Satzglied-und Wortstellung. Göttingen: Vandenhoeck \& Ruprecht.

Birkner, Karin (2008): Relativ(satz)konstruktionen im gesprochenen Deutsch. Syntaktische, prosodische, semantische und pragmatische Aspekte. Berlin / New York: De Gruyter.

Burkhardt, Armin (2003): Das Parlament und seine Sprache. Studien zu Theorie und Geschichte parlamentarischer Kommunikation. Tübingen: Niemeyer.

Cirko, Lesław (2013): Dem Gesagten Relief geben. In: Engel, Ulrich (Hg.): Argumentieren. Sprechen im deutsch-polnischen Kontrast. Wroctaw / Dresden: ATUT / Neisse, 55-77.

Dalmas, Martine (2013): Strategien der Fokussierung: eine 'spannende' Geschichte - und eine Revidierung mancher Vorurteile. In: Adam, Séverine (Hg.): ,Informationsstrukturen' im gesteuerten Spracherwerb. Französisch - Deutsch kontrastiv. Frankfurt/M.: Lang, 67-77. 
Eggs, Frederike (2011): Zur Funktionalität des Konnektors „geschweige denn“. In: Breindl, Eva / Ferraresi, Gisella / Volodina, Anna (Hg.): Satzverknüpfungen. Zur Interaktion von Form, Bedeutung und Diskursfunktion. Berlin / New York: De Gruyter, 229-262.

Eisenberg, Peter et al. ( $\left.{ }^{8} 2009\right)$ : Duden. Die Grammatik. Mannheim: Duden-Verlag.

Engebretsen, Steinar (2016): Deutsche Cleft-Sätze - wie vielseitig sind sie eigentlich? Eine internetbasierte Bestandsaufnahme. In: Deutsche Sprache 1/2016, 43-76.

Engel, Ulrich (2009): Deutsche Grammatik - Neubearbeitung. München: Iudicium.

Friesdorf, Marita (2011): Bundestagsreden: Analyse und Bewertung der redaktionellen Bearbeitung. http://www.verlag-gespraechsforschung.de/2011/pdf/bundestagsreden.pdf [30.11.2019].

Grochowski, Maciej / Kisiel, Anna / Żabowska, Magdalena (2014): Stownik gniazdowy partykutpolskich [Nestwörterbuch polnischer Partikeln]. Kraków: PAU.

Günthner, Susanne (2006): „Was ihn trieb, war vor allem Wanderlust“ (Hesse: Narziß und Goldmund). Pseudocleft-Konstruktionen im Deutschen. In: Günthner, Susanne / Imo, Wolfgang (Hg.): Konstruktionen in der Interaktion. Berlin / New York: De Gruyter, 59-90.

Kisiel, Anna (2012): Polskie partykuty wyróżniajace. Studium semantyczne [Polnische hervorhebende Partikeln. Eine semantische Studie]. Warszawa: SOW.

Klein, Josef (1991): Politische Textsorten. In: Brinker, Klaus (Hg.): Aspekte der Textlinguistik. Hildesheim / Zürich / New York: Olms, 245-278.

Klein, Josef (2001): Gespräche in politischen Institutionen. In: Brinker, Klaus / Antos, Gerd / Heinemann, Wolfgang / Sager, Sven F. (Hg.): Text-und Gesprächslinguistik. Ein internationales Handbuch zeitgenössischer Forschung. HSK 16.2. Berlin / New York: De Gruyter, 1589-1606.

Koch, Peter / Oesterreicher, Wulf (1985): Sprache der Nähe - Sprache der Distanz. Mündlichkeit und Schriftlichkeit im Spannungsfeld von Sprachtheorie und Sprachgeschichte. In: Romanistisches Jabrbuch 36/1985, 15-43.

Métrich, René / Faucher, Eugène (2009): Wörterbuch deutscher Partikeln. Berlin / New York: De Gruyter.

Poźlewicz, Agnieszka (2011): Syntax, Semantik und Pragmatik der Operatorpartikeln des Deutschen. Versuch einer Systematik. Frankfurt/M.: Lang.

Poźlewicz, Agnieszka (2014): Phrasen als Mittel der textuellen Exposition. In: Linguistische Treffen in Wroctaw 10/2014, 113-122.

Rytel-Schwarz, Danuta u. a. (2012): Deutsch-polnische kontrastive Grammatik. Bd. 4: Die unflektierbaren Wörter. Hildesheim / Zürich / New York: Olms.

Rytel-Schwarz, Danuta u. a. (2018): Deutsch-polnische kontrastive Grammatik. Bd. 2: Der Satz. Hildesheim / Zürich / New York: Olms.

Tworek, Artur (2016): Fokusakzente als rhetorische Hervorhebungsmarker in der gesprochenen Wissenschaftssprache. Eine deutsch-polnische vergleichende Signaluntersuchung. In: Studia Linguistica 35/2016, 221-233. DOI: 10.19195/0137-1169.35.12

Zeh, Wolfgang (1989): Theorie und Praxis der Parlamentsdebatte. In: Schneider, Hans-Peter / Zeh, Wolfgang (Hg.): Parlamentsrecht und Parlamentspraxis in der Bundesrepublik Deutschland. Berlin / New York: De Gruyter, 917-938. 